\title{
Entre castidad y lujuria: sexo y amor en Bizancio
}

\author{
Segundo Coloquio Bizantino de la Universidad de Buenos Aires \\ Instituto de Filología Clásica, Secc. de Filología Medieval \\ 28 y 29 agosto 2017
}

\section{Presentación}

\section{Q Pablo Cavallero Tomás Fernández}

El segundo Coloquio internacional de Estudios Bizantinos de la UBA (agosto de 2017), coorganizado con la Katholieke Universiteit Leuven, tuvo por tema el sexo y el erotismo en Bizancio, en el marco de la castidad y la lujuria como vertientes posibles.

La mayor diferencia con el primer Coloquio, realizado dos años antes (agosto de 2015), probablemente haya sido la mayor internacionalización del encuentro. En esta ocasión, la UBA contó con la visita de especialistas de Dinamarca, Israel, Italia, España, Chile y Alemania, que tuvieron un intercambio fluido con los equipos locales.

Varias de las contribuciones argentinas y extranjeras pueden leerse en el volumen que aquí se publica. Al recoger las ponencias, ya transformadas en artículos, esperamos dar un pequeño paso a favor del progreso de los estudios sobre el amor bizantino, respecto del cual todavía falta una visión de conjunto o una colección de case-studies suficientemente abarcativa; $\mathrm{y}$, a la vez, ponernos en contacto de manera más directa $-\mathrm{y}$ en nuestro propio medio- con la comunidad internacional. 
